\title{
Interpreting Long-Term Trends in Time Series Intervention Studies of Smoke-Free Legislation and Health
}

\author{
Ruth Salway ${ }^{1}$, Michelle Sims ${ }^{2, *}$ and Anna B. Gilmore ${ }^{2}$ \\ ${ }^{1}$ Department for Health, University of Bath, Claverton Down, Bath, BA2 7AY, UK \\ ${ }^{2}$ UK Centre for Tobacco and Alcohol Studies, Department for Health, University of Bath, Claverton Down, \\ Bath, BA2 7AY, UK
}

\begin{abstract}
Background: Numerous studies have investigated the impact of smoke-free laws on health outcomes. Large differences in estimates are in part attributable to how the long-term trend is modelled. However, the choice of appropriate trend is not always straightforward. We explore these complexities in an analysis of myocardial infarction (MI) mortality in England before and after the introduction of smoke-free legislation in July 2007.

Methods: Weekly rates of MI mortality among men aged 40+ between July 2002 and December 2010 were analysed using quasi-Poisson generalised additive models. We explore two ways of modelling the long-term trend: (1) a parametric approach, where we fix the shape of the trend, and (2) a penalised spline approach, in which we allow the model to decide on the shape of the trend.

Results: While both models have similar measures of fit and near identical fitted values, they have different interpretations of the legislation effect. The parametric approach estimates a significant immediate reduction in mortality rate of $13.7 \%(95 \% \mathrm{Cl}: 7.5,19.5)$, whereas the penalised spline approach estimates a non-significant reduction of $2 \%$ $(95 \% \mathrm{Cl}:-0.9,4.8)$. After considering the implications of the models, evidence from sensitivity analyses and other studies, we conclude that the second model is to be preferred.

Conclusions: When there is a strong long-term trend and the intervention of interest also varies over time, it is difficult for models to separate out the two components. Our recommendations will help further studies determine the best way of modelling their data.
\end{abstract}

Keywords: Smoke-free law, myocardial infarction, mortality, second-hand smoke, passive smoke.

\section{INTRODUCTION}

There is substantial evidence to suggest adverse health effects of second-hand smoke [1-8] which has led to the introduction of smoke-free legislation (SFL) in a number of jurisdictions. For example, in England legislation was introduced on 1 July 2007, when all enclosed workplaces and public places, with a few exceptions, became smoke-free. Similar legislation has been passed in other European countries such as Scotland, Spain and Italy, and at state and local government level in the US. Numerous studies have investigated the effect of such legislation on health outcomes such as myocardial infarction (MI) and asthma $[9,10]$, but estimates vary dramatically. For example, reductions in $\mathrm{Ml}$ hospital admissions range from $2 \%$ [11] to $40 \%$ [12] and MI mortality from 4\% [13] to $18 \%$ [14]. These large differences are attributable in part to the methodology used.

Hospital admissions and mortality rates for coronary heart disease have been declining across Europe and North America [15-18]. However, few studies evaluating the impact of SFL have adequately taken

*Address correspondence to this author at the Tobacco Control Research Group, Department for Health, University of Bath, Claverton Down, Bath, BA2 7AY, UK; Tel: +44 1225384059; E-mail: m.sims@bath.ac.uk this long-term trend (LTT) into account. For example, among studies that focus on hospital admissions, a number have used a 'before and after' study design which ignores the background trend completely (for example $[12,19,20])$. A common assumption is that the trend is linear on the log scale [11, 21-25] but only in very few cases $[11,21]$ is this assumption is justified or checked.

There are few studies of SFL and MI mortality. The background trend for $\mathrm{MI}$ mortality is even more pronounced than for hospital admissions, but studies have used similar modelling approaches. A study in Spain used the before and after design that takes no account of the LTT [26]. Another study in the US allows differences between years, but without imposing a specific trend [13]. Others have assumed a linear trend on the log scale, either directly $[14,27,28]$ or implicitly [29]. Only one of these reported checking whether the linear trend was appropriate [14].

Yet modelling the LTT is important for a number of reasons. As the trend is decreasing over time, looking at $\mathrm{MI}$ reductions without taking this trend into account will over-estimate any reduction associated with SFL. For example, studies that ignore the trend produce higher estimates of a significant reduction in 
admissions; up to $40 \%$ [12] rather than more modest reductions (2\%-11\%) among studies that do any sort of controlling for trend [11, 21-25]. Moreover, it is important to justify any assumptions made in order to prevent erroneous conclusions.

However, modelling the LTT appropriately is not straightforward [30-32]. Changes in, say, the MI mortality rate over time are attributable to a number of different factors, which may include changes in risk factors, treatment and diagnosis. Because these are not modelled directly their cumulative effect is combined into one single estimate of trend that represents all these time-varying unmeasured confounders. Choosing between different ways to model the trend also becomes problematic, as there is a limit to the information available in the data. As models become more complicated, data quality remains the same and models become harder to interpret. Both the LTT and the intervention change over time and potential smoke-free effects may be substantially smaller than the trend. This can cause problems in separating out the two components. Two studies exploring the impact of SFL on $\mathrm{Ml}$ admissions have found contradictory conclusions depending on how the trend is modelled [30, 31].

This paper focuses on the complexities of modelling the LTT in an analysis of MI mortality in England before and after the introduction of SFL on $1^{\text {st }}$ July 2007 . The aim of this paper is to examine how to choose between models. It is anticipated that this will help further studies determine the best way of modelling their data in this controversial area.

\section{DATA}

We use weekly counts of MI mortality in men aged 40 years and over. The raw mortality data show strong seasonal trends and a pronounced LTT with mortality rates decreasing over the time period (Figure 1). Unadjusted mortality rates gives 3.3 per 100,000 in the five years pre-legislation and 2.3 per 100,000 in the three and a half years post-legislation; a reduction of a third. It would be naĩve, however, to conclude that the SFL has reduced MI mortality by $30 \%$. It is clear that mortality has been declining for some time before the legislation was introduced indicating that there are other relevant factors changing over time. These need to be considered when determining the effect of the legislation. As this is a retrospective ecological study we do not have data on individuals' behaviour or cardiovascular risk factors and without being able to model these factors explicitly, we can only model them generally via a LTT.

We look at two ways of modelling the LTT, but the underlying modelling approach remains the same. We specify an over-dispersed quasi-Poisson for the weekly counts and include a binary predictor representing the introduction of SFL, weekly population estimates as an offset variable and the following covariates: temperature, flu, month and a Christmas holiday indicator [33-36]. The month of the year variable is

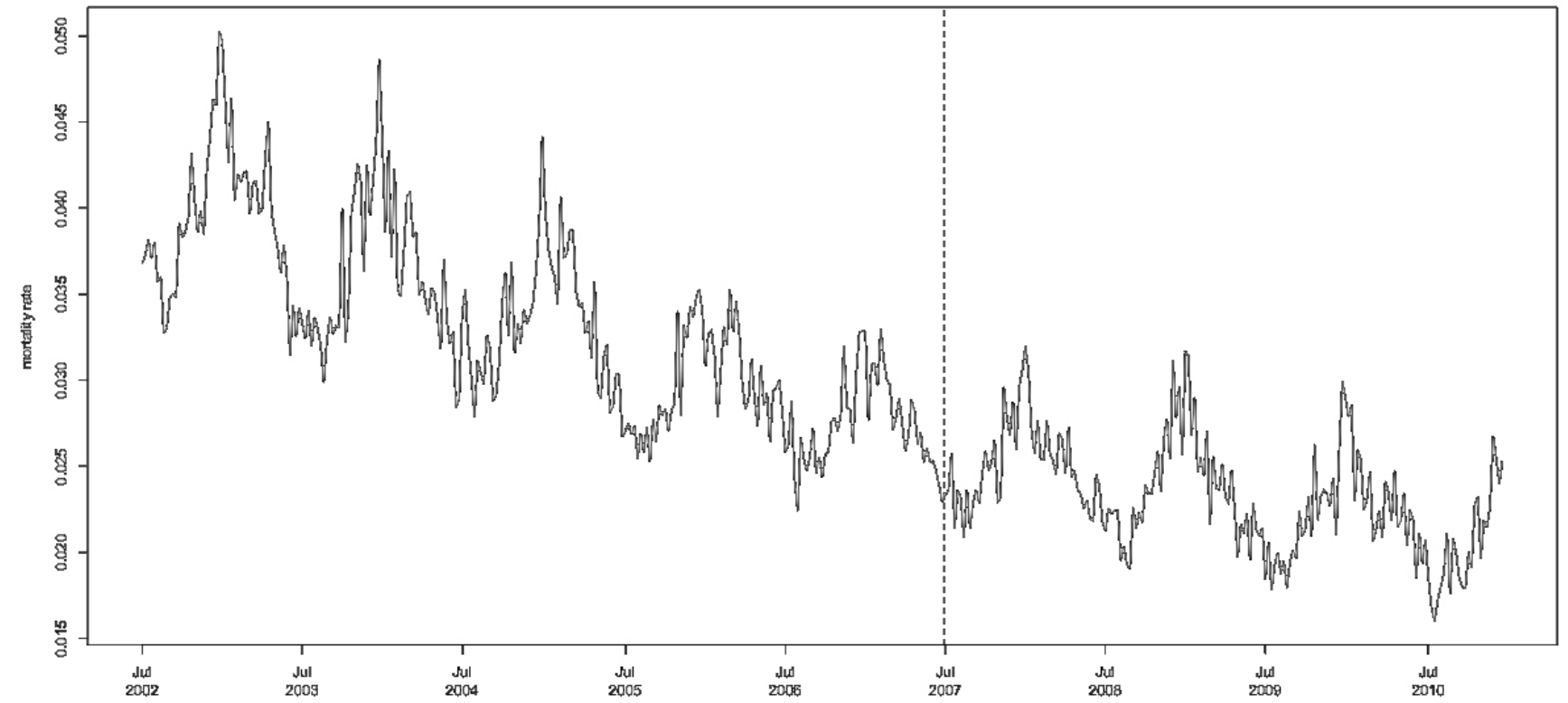

Figure 1: Raw weekly MI mortality rates over the study period for men aged $40+$. The dashed line represents the date of smoke-free legislation. 
modelled as a cyclic cubic spline to pick up the seasonal variation that is evident in Figure 1; Further details are given in the Appendix.

\section{MODELLING LONG-TERM TRENDS}

Since we fit a Poisson model to these data, all modelling is done on the log-mortality scale. We look at two approaches to modelling the LTT. The first is a parametric approach where we fix the shape of the trend. This might be suitable if we know the shape of the trend, excluding any smoke-free effects, from some other source (e.g. a similar country without SFL). Alternatively, it provides a starting point with an assumption to be checked. It has the advantage that the additional structure imposed can separate out the background patterns from the intervention effect. The disadvantage is that if the specified trend is incorrect, the model may miss what is really going on: we might observe smoke-free effect that isn't really there or alternatively miss a genuine effect.

An alternative is to allow the data to decide on the shape of the LTT. The advantage of this approach is that it does not force preconceived structure on the model, the data instead dictating the shape of the trend. However, there is a cost in terms of loss of degrees of freedom; that is, the model uses fewer pieces of independent information. A key disadvantage is that the data must do many things at once, identifying both the LTT and any smoke-free effects. Modelling a LTT in this way essentially picks up timevarying factors that are not modelled elsewhere. Unfortunately, because the presence of SFL also varies over time, if there are any changes around the date of the legislation the model is forced to choose between attributing them to either the LTT or to the legislation. This is particularly a problem in applications of this sort, where the LTT is very strong while any potential intervention effects may be comparatively small.

\section{Model 1: Linear Trend (on the Log Scale)}

A common choice in studies of SFL and MI mortality is to assume a linear trend on the log mortality scale $[27,28]$, which corresponds to an exponential-shaped trend for the data. We find no significant effect of the SFL if we fit such a trend. However, if we introduce an interaction term between the legislation and the slope of the time trend, then both the SFL variable and the

Table 1: Comparison of Models 1 and 2

\begin{tabular}{|c|c|c|}
\hline Covariate & $\begin{array}{c}\text { Model } 1 \\
\text { (linear trend with interaction) }\end{array}$ & $\begin{array}{c}\text { Model } 2 \\
\text { (smooth spline trend) }\end{array}$ \\
\hline \multicolumn{3}{|l|}{ Time trend } \\
\hline Degrees of freedom ${ }^{a}$ & & 2.44 \\
\hline \multicolumn{3}{|l|}{$\%$ reduction per six months $(95 \% \mathrm{Cl})$} \\
\hline Pre-legislation & $4.37(4.13 \text { to } 4.62)^{b}$ & \\
\hline Post-legislation & $3.16(2.67 \text { to } 3.64)^{b}$ & \\
\hline \multicolumn{3}{|l|}{ Smoke-free effect } \\
\hline$\%$ reduction $(95 \% \mathrm{Cl})$ & $13.68(7.49 \text { to } 19.46)^{b}$ & $2.02(-0.87$ to 4.82$)$ \\
\hline \multicolumn{3}{|l|}{ Other covariates included } \\
\hline Seasonal trend (cyclic spline) & Yes & Yes \\
\hline Temperature in previous week (linear) & Yes & Yes \\
\hline $\log (f \mid u)$ & Nonlinear & Nonlinear \\
\hline Christmas holidays & Yes & Yes \\
\hline Over-dispersion parameter & 1.30 & 1.30 \\
\hline \multicolumn{3}{|l|}{ Measures of fit } \\
\hline GCV & 1.385 & 1.388 \\
\hline Adjusted $\mathrm{R}^{2}$ & 0.907 & 0.907 \\
\hline$\%$ deviance explained & $93.2 \%$ & $93.2 \%$ \\
\hline Residual df (estimated) & 427.4 & 426.9 \\
\hline
\end{tabular}

${ }^{a}$ degrees of freedom for penalised spline. A value of 1 is a straight line, with larger values representing increased wiggliness. ${ }^{b} p<0.05$. 
interaction term are statistically significant (Table 1, $p<0.001$ for both). This separates the LTT into two pieces: on the log scale, a straight line before and after the legislation with differing slopes plus a jump at the date of the legislation (Figure 2). However, this is a complex relationship where after the SFL is introduced there is an immediate reduction in mortality (13.7\%; $95 \% \mathrm{Cl}: 7.5$ to 19.5$)$ combined with a decrease in the rate of change over time $(3.2 \%$ per six months; $95 \% \mathrm{Cl}$ : 2.7 to 3.6). The latter means that although mortality continues to decline, it does so at a slower rate than before the legislation (4.4\% per six months; $95 \% \mathrm{Cl}: 4.1$ to 4.6) (Table 1).

\section{Model 2: Smooth Spline Trend}

Fitting a penalised spline to the LTT models the trend on the log scale as a nonlinear cubic spline with 2.4 degrees of freedom; that is, a curve rather than a straight line. Figure 2 shows the shape of this trend (again, on the log scale); there a slight concave curve towards the middle of the study period. The mortality rate is decreasing over time, but this decrease becomes less steep towards the end of the study period. SFL is associated with a non-significant $(\mathrm{p}=0.17)$ reduction in mortality of $2.0 \%(95 \% \mathrm{Cl}:-0.9$ to 4.8; Table 1).

\section{Comparison of the Two Models}

The over-dispersion parameter was estimated at 1.3 for both models, suggesting the presence of a small amount of unmeasured confounding. For each model,

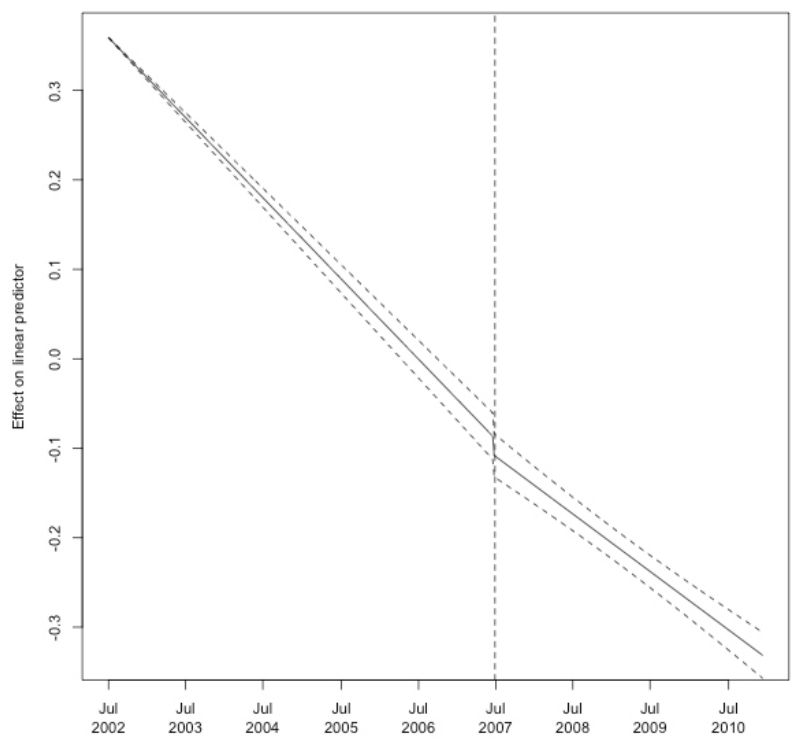

the model-building process was started from scratch; the same covariates were included in both models and all were significant with very similar coefficients (identical to two decimal places). Both models are nearly identical in terms of fitted values, GCV score (broadly equivalent to AIC and interpreted in the same way) and percentage deviance explained. Residual plots for the two models are near-identical; residuals did not deviate substantially from model assumptions, and residual short-term auto-correlation was not present. It is not possible to statistically test the difference between the two models as they are not nested.

\section{CHOOSING BETWEEN MODELS}

Both models are consistent with the data, but each tells a very different story. Statistically we cannot choose between them; there is insufficient information in the data. Generally we prefer less complex models, all other things being equal, but in this case there is very little between the two. The estimated residual degrees of freedom are within 0.5 of each other so both models use almost the same amount of information. In order to choose between the two models we need to explore more closely the following points: sensitivity analyses, interpretation of the models and supporting external evidence.

\section{Sensitivity Analyses}

Consistency over a range of different scenarios adds weight to the conclusions and means that results

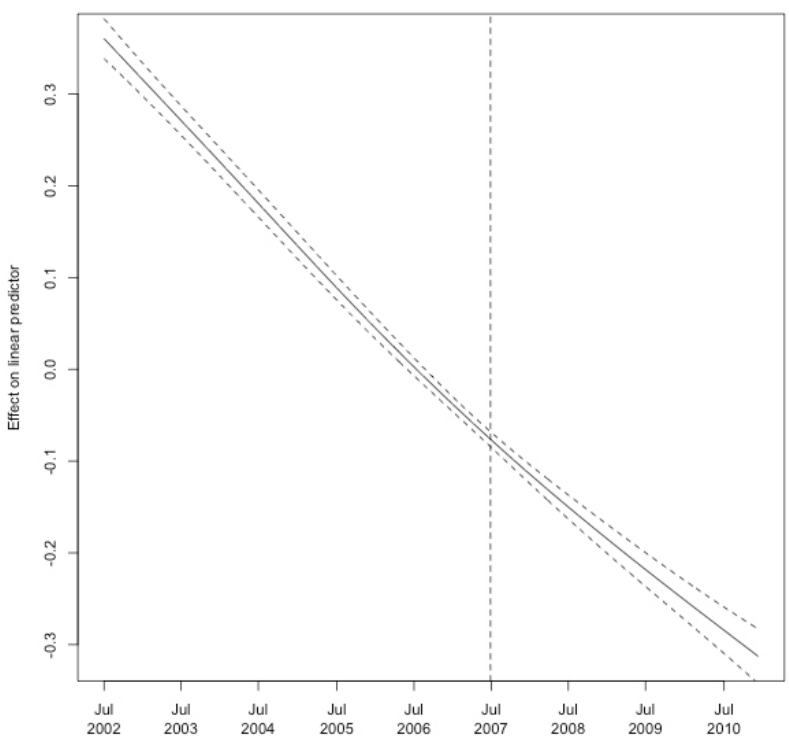

Figure 2: Time and smoke-free effect on the log mortality scale: Model 1 (left) and Model 2 (right). The dashed line represents the date of smoke-free legislation. 
are less likely to be due to random variation. If one model is highly sensitive to changes then it makes sense to prefer the more robust one for its consistency. We consider sensitivity to how the covariates are modelled, the length of the pre and post legislative periods and the date of the introduction of SFL.

\section{Modelling of Covariates}

We tried different ways of modelling the covariates, for example using linear terms instead of splines for the flu rates, and using a categorical variable for month. We also tried different parameters for the penalised spline functions. All relationships remained the same, coefficients were very similar and model conclusions for both models were unchanged.

\section{Length of Study Period}

We tried varying the length of pre and post legislative data. This is complicated to interpret as we wouldn't necessarily expect models to be consistent across all pre and post time periods, but here we focus on general patterns.

For all variations in length of the pre and post legislative periods, Model 2 consistently concludes a nonsignificant smoke-free effect, although the shape of the trend varies between linear and slightly concave. Model 1 is less consistent, and only finds a significant legislation effect (and a complex interaction) when there is a long post-legislative period (Table 2).

This suggests that the problem of inconsistent models is related to longer follow-up periods. It is possible that as more post-legislative data is included, analysis is complicated by more complex smoke-free effects, such as delayed effects, effects that vary over time or changes in other factors, but neither model is suitable to model or detect such effects.

\section{Date of Legislation}

We repeated the analysis using fifteen false dates for the SFL chosen randomly between July 2004 and July 2010. Model 1 shows significant smoke-free effects for dates between 2005 and 2008 (Figure 3). This suggests that Model 1 is consistent with dates between 2005 and 2008, but not necessarily fixed at the actual date. Model 2 does not show significant effects suggesting that the lack of significant legislation effect is consistent across changes in dates and not due to random variation.

\section{Interpretation}

\section{Similarities and Differences}

It is easy to focus on the obvious difference between the two models; one concludes that there is a significant smoke-free effect while the other concludes the opposite. But a closer look at how the LTT and SFL effects are being modelled over time (Figure 2) highlights the similarities. The fundamental difference is that in Model 1 the time trend on the log scale is modelled as two straight lines with differing slopes, whereas in Model 2 it is a slight curve.

This can be seen more clearly in derivative plots which show the rate at which the decline in (log)

Table 2: Effect of Varying the Amount of Pre and Post-Legislative Data ${ }^{a}$

\begin{tabular}{|c|c|c|c|}
\hline & \multicolumn{3}{|c|}{ Post-legislative period } \\
\hline & Short (1 year) & Medium (2 years) & Long (3.5 years) \\
\hline \multicolumn{4}{|c|}{ Pre-legislative period: Medium (3.5 years) } \\
\hline Model 1 & \multirow[t]{2}{*}{$\begin{array}{l}\text { Drop interaction term and linear trend } \\
\text { No legislation effect }(p=0.50)\end{array}$} & $\begin{array}{l}\text { Drop interaction term } \\
\text { No legislation effect }(p=0.88)\end{array}$ & $\begin{array}{l}\text { Significant interaction model: } \\
\text { legislation and interaction both } \\
\mathrm{p}<0.001\end{array}$ \\
\hline Model 2 & & $\begin{array}{l}\text { Nonlinear trend } \\
\text { No legislation effect }(p=0.45)\end{array}$ & $\begin{array}{l}\text { Nonlinear trend } \\
\text { No legislation effect }(p=0.15)\end{array}$ \\
\hline \multicolumn{4}{|c|}{ Pre-legislative period: Long (5 years) } \\
\hline Model 1 & \multirow[t]{2}{*}{$\begin{array}{l}\text { Drop interaction term and linear trend } \\
\text { No legislation effect }(p=0.38)\end{array}$} & $\begin{array}{l}\text { Drop interaction term } \\
\text { No legislation effect }(p=1.00)\end{array}$ & $\begin{array}{l}\text { Significant interaction model: } \\
\text { legislation and interaction both } \\
p<0.001\end{array}$ \\
\hline Model 2 & & $\begin{array}{l}\text { Nonlinear trend } \\
\text { No legislation effect }(p=0.50)\end{array}$ & $\begin{array}{l}\text { Nonlinear trend } \\
\text { No legislation effect }(p=0.17)\end{array}$ \\
\hline
\end{tabular}

${ }^{a}$ For Model 1 , if the interaction effect was nonsignificant $(p>0.05)$ it was dropped from the model to become a linear time trend model with just a legislation effect. For Model 2, if the estimated degrees of freedom for the time trend was 1 (straight line) the spline was replaced with a linear time trend. In some cases, both simplifications occurred and thus both modelling approaches resulted in the same linear time trend model with no interaction (simple linear model); these cases are indicated in the table with combined cells. Bold indicates those models that have a statistically significant legislation effect. Shaded cells indicate where the two models disagree. The bottom right corner (long pre and long post-legislative period) corresponds to the full data. 


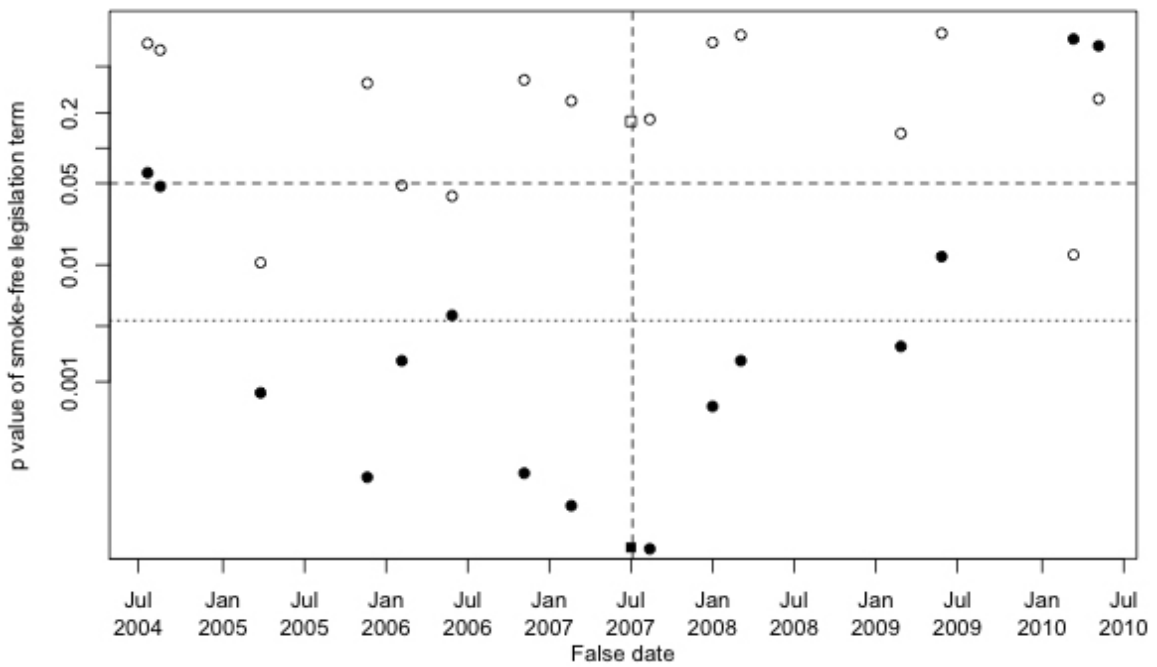

Figure 3: p-values (on log scale for clarity) for smoke-free legislation effect for Models 1 (solid dots) and Models 2 (open dots) for false dates of legislation. Squares indicate data from true legislation. Dashed line is $p=0.05$ and dotted line is $\mathrm{p}=0.05 / 15=0.003$, adjusted for multiple testing.

mortality is changing (Figure 4). In Model 1 the rate of change is always constant, but after the legislation the mortality rate declines at a slower rate than before. In Model 2, there are three main stages. Initially mortality declines at a steady rate (flat line) and then around the end of 2004 the decline begins to slow down (decreasing slope). The decline in mortality then continues to slow over the remainder of the study period, until around the beginning of 2010, when mortality declines constantly again (flat line).

So the two models are actually telling us much the same thing. Both derivative plots show roughly level rates of change at the beginning and the end of the study period at about the same level. Both models

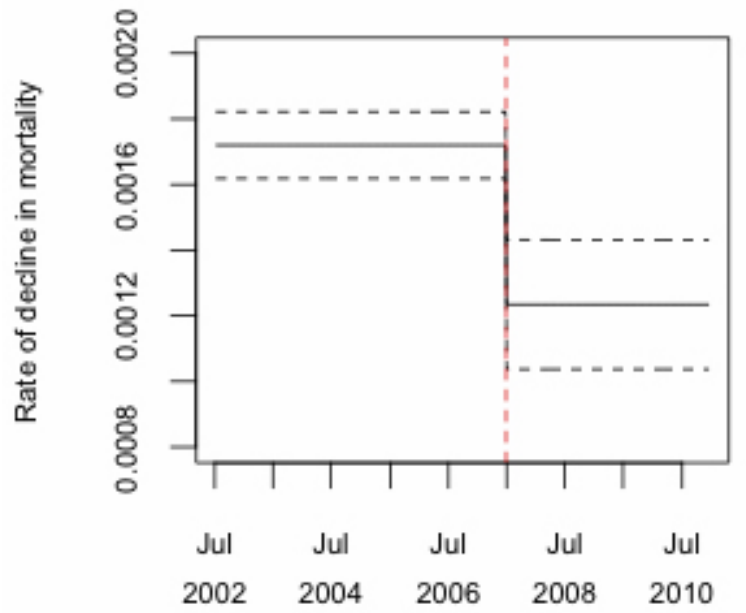

show a change in that rate somewhere in the middle of the study period; the difference is when that change occurs and over what period. Model 1 ascribes this to a sudden change at a single point in time (the SFL date, fixed externally) while Model 2 shows the mortality decline slowing down gradually over the five year period between the beginning of 2005 and 2010 .

\section{Estimating the Benefits of Smoke-Free Legislation}

It is important that models make sense in the real world, especially if they are to be used to make predictions. With Model 1, which concludes that the SFL has an effect, we might wish to estimate how many deaths have been saved as a result. In the first six months Model 1 predicts 104 deaths averted, with

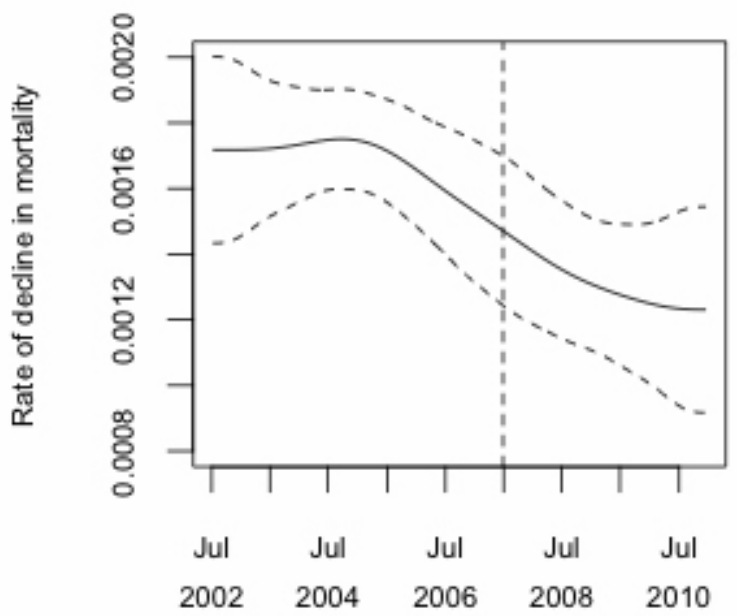

Figure 4: Derivative plots for Model 1 (left) and Model 2 (right). The derivative plot shows the rate at which the log mortality rate is declining; a flat line indicates a constant rate of decline, with increasing and decreasing lines indicating a speeding up and slowing down of the decline in MI mortality respectively. A linear time trend (on the log mortality scale) is equivalent to a constant change in rate over time. The dashed lines represent $95 \%$ confidence intervals. 
another 11 by the end of the first year (Figure 5). The predictions become negative from the second half of 2008; that is, the model predicts additional deaths as a result of the legislation.

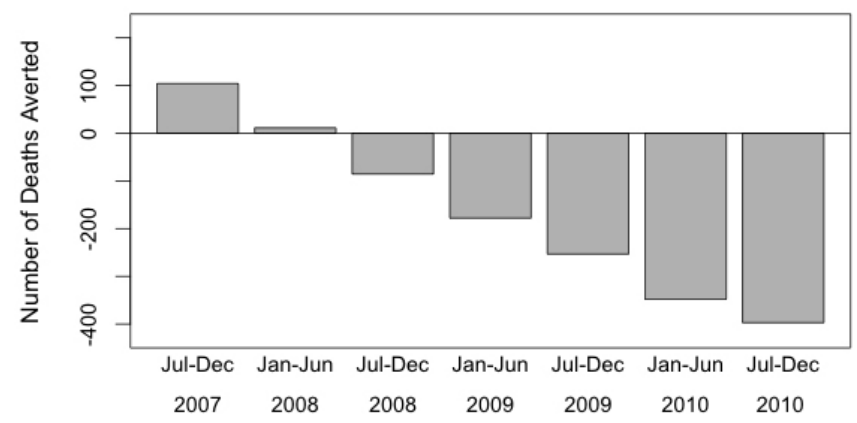

Figure 5: Predicted number of deaths averted due to smokefree legislation (estimated from Model 1) in six-monthly intervals.

There are a number of reasons why this could occur. The model could be correct and the legislation has indirectly caused additional deaths. While this sounds counter-intuitive, one possible explanation is that this is evidence of delayed deaths. That is, those who would have died in the first six months have survived another six months or year longer. If mortality is delayed in this way, then we might see this pattern initially, but such a pattern could not continue and eventually the deaths averted would return to zero. However, Model 1 is unable to adequately model this; because it is linear the number of deaths is constrained to increase in this way forever. Alternatively, there is something wrong with the model. Either the LTT based on the pre-legislative data is not representative of subsequent trends or SFL effects are not modelled correctly (estimates of post-legislation deaths are incorrect), or the model is missing some other important factors that change before and after (both are incorrect, but by different amounts).

This casts doubt on the suitability of Model 1. Either there is a genuine negative impact of SFL, or Model 1 is unable to adequately model what is going on.

\section{Supporting Evidence}

There is some evidence from other countries to suggest that the decline in mortality rates is starting to flatten [15, 37]. This is generally attributed to changes in treatments and background risk factors, and is seen in countries both with and without SFL. It could thus be argued that the interaction in Model 1 is due to changing background factors, rather than the SFL. It is also not possible for the mortality rate to decline linearly forever, although that may be a reasonable approximation for the current time.

Other studies of $\mathrm{MI}$ hospital admissions and mortality have seen significant smoke-free effects [9], although the evidence for MI mortality is inconclusive [13, 14, 26-29]. While one study of MI mortality has investigated interaction effects, no significant results have been found [28]. There are no studies to date that have predicted the kind of additional deaths we see in Model 1 here.

Estimated reductions in MI mortality post-smokefree range from 4 to $18 \%$ among studies which include a LTT $[13,14,27-29]$ and half of these reported nonsignificant reductions [13, 28-29]. Model 1 is at the high end of these estimates at $14 \%$, while the nonsignificant reduction of $2 \%$ from Model 2 falls just below the bottom of this range. Reductions for mortality are generally lower than for hospital admissions; an analysis of hospital admissions for the England SFL found a reduction of $3 \%$ among men [11].

External evidence is therefore consistent with Model 2: the gradual slowing down of the mortality decline is documented elsewhere, the estimated reduction is broadly within the range found in other studies, and is lower than that found in the English hospital admissions study. While Model 1 has a significant smoke-free effect and the estimate is within the range found elsewhere, there is limited support for a linear trend and the predictions of additional deaths are unsupported.

\section{DISCUSSION}

In this paper we compared two approaches to modelling the LTT in a study of the impact of SFL on MI mortality in men aged 40 or over. While both models include the same covariates and have very similar covariate parameters, fitted values and GCV score, they differ in their conclusions about the SFL effect. After considering the evidence presented here (summarised in Table A1, Appendix), Model 2 is to be preferred to Model 1, and conclude that there is a nonsignificant reduction of $2 \%$ in $\mathrm{Ml}$ mortality associated with the SFL.

The discrepancy between the two models occurs because there is a strong LTT with mortality decreasing over time and the intervention of interest also varies over time and so it is difficult for any model to separate out the two time effects. 
We have looked at a number of different ways to try and understand what lies beneath this apparent contradiction: sensitivity analyses, considering the implications of the models and exploring external evidence. As we have seen, Model 2 is consistent with the external evidence and robust to changes in covariate modelling, date of legislation and the length of pre and post-legislative period. It is arguably slightly more complicated than Model 1, and there is the danger that a potential smoke-free effect (especially if it is comparatively small) has been absorbed into the LTT. The estimated reduction is very small and it is possible that that the model lacks power.

In contrast, Model 1 has a complex interaction effect not seen in other studies of this type. The interpretation of this effect is complex with the ongoing mortality decline slowing down after the legislation, and this leads to the surprising predictions of additional deaths after one year. Sensitivity analyses suggest that significant smoke-free effects could be found for several dates either side of the true date of legislation, and that the conclusions of the model change depending on how much post-legislative data is included. All these combine to undermine trust in this model, and suggest that it is inadequate.

The sensitivity analysis surrounding the length of the study period raises some interesting questions. A reasonable period of pre-legislative data is required to 'set the scene' and pick up LTTs. However, we only encountered conflicting models once we had over three years of post-legislative data. There is a potential trade-off here between having sufficient post-legislative data to be able to observe any impact and having so much that it includes other post-legislative changes. For example, MI mortality depends on many factors that are changing over time. Two years post-legislation we might expect that these factors have not changed greatly, and be able to observe a noticeable legislation effect. At ten years post-legislation, however, the cumulative effect of changes in other factors will vastly out-weigh the change from a single intervention point in time. There is an important question here concerning the amount of data needed to pick up an intervention effect if it exists, without the effect becoming lost among other factors.

Although the majority of this paper has focused on identifying which model is better the truth here is that neither is a very good model because the underlying data are so limited. With these data we are restricted to an ecological study, with all the problems that arise when we don't have individual data on mortality outcomes and crucial risk factors. The approach of our preferred Model 2 is to capture all these unmeasured time-varying confounders in one LTT, but this is clearly a poor substitute for being able to model them directly and risks misattributing changes.

Poor data means we need more complex models to draw conclusions. However, there is a limit to what a model can do without good quality data, however complex. As models become complex, they tend to be driven by model assumptions rather than the data. While assumptions can allow us to tease out subtle effects, we need to check such assumptions very carefully.

\section{ACKNOWLEDGEMENTS}

The authors would like to thank the South West Public Health Observatory (now the Knowledge and Intelligence Team (South West) in Public Health England) for access to the mortality data, and the Royal College of General Practitioners' research and surveillance centre for providing the weekly influenza rates.

\section{COMPETING INTERESTS}

There are no competing interests.

\section{FUNDING}

This work was undertaken by the University of Bath which received funding from the Department of Health's Policy Research Programme. The views expressed in the publication are those of the authors and not necessarily those of the Department of Health. $M S$ and $A B G$ are members of the UK Centre for Tobacco and Alcohol Studies (UKCTAS), a UK Centre for Public Health Excellence. Funding to UKCTAS from the British Heart Foundation, Cancer Research UK, the Economic and Social Research Council, the Medical Research Council and the National Institute of Health Research, under the auspices of the UK Clinical Research Collaboration, is gratefully acknowledged.

The funders had no role in the study design, data collection and analysis, interpretation of data, decision to publish, or preparation of the manuscript.

\section{APPENDIX}

\section{Mortality Data}

We identified all deaths in males aged 40 years and over, resident in England, with a date of death between 
$1^{\text {st }}$ July 2002 and 31st December 2010 and a primary cause of death of myocardial infarction (ICD-10 code $\left.121^{1}\right)$. Data were obtained from the UK's Office for National Statistics and included age and sex; there were no missing data for either variable. This comprises five years of data before the legislation was introduced and three and a half years after. Data were aggregated to weekly mortality counts, according to ISO week numbers, and restricted to full weeks (so dates after $26^{\text {th }}$ December 2010 were excluded)

We include weekly population estimates as a (log) offset and include other covariates as follows:

- a binary predictor variable representing the smoking ban with a value of 0 before the smoking ban was introduced, and 1 afterwards

- a month of the year variable as a cyclic cubic spline to pick up the seasonal variation;

- weekly mean temperature from the previous week (linear term);

- $\quad$ log-transformed weekly flu rates as a cubic spline;
- a Christmas holiday indicator (with a value of 1 for the first and last weeks of the year and 0 otherwise);

Splines were included as penalised splines via Generalized Additive Models (GAMs) using the gam and gamm functions from the mgcv library in $\mathrm{R} 2.12 .1{ }^{2}$ Further details about the model building process can be found elsewhere. ${ }^{3}$

${ }^{1}$ World Health Organisation. International statistical classification of diseases and related health problems, Tenth Revision Geneva: World Health Organisation, 1992.

${ }^{2}$ Wood SN. Generalized Additive Models: An introduction with R. Boca Raton, Florida: Chapman and Hall/CRC, 2006.

${ }^{3}$ Salway R, Sims, M., Gilmore, A. B. Is there an immediate reduction in myocardial infarction mortality after the introduction of smoke-free legislation in England? Under Review.

Table A1: Comparison of the Two Models: Summary of the Factors Considered

\begin{tabular}{|c|c|c|}
\hline & Model 1 & Model 2 \\
\hline \multicolumn{3}{|c|}{ Description } \\
\hline & $\begin{array}{l}\text { - } \quad \text { Linear time trend on the log mortality scale } \\
\text { - } \quad \text { Interaction between time and date of legislation }\end{array}$ & - Nonlinear time trend \\
\hline \multicolumn{3}{|l|}{ Results } \\
\hline & - Significant interaction and smoke-free effect & - Non-significant smoke free effect \\
\hline \multicolumn{3}{|c|}{ Statistical Comparison } \\
\hline & - $\quad$ Fitted values and measures of fit the same as Model 2 & $\begin{array}{ll}\text { - } & \text { Fitted values and measures of fit the same as Model } 1 \\
\text { - } & \text { Slightly more complex model }\end{array}$ \\
\hline \multicolumn{3}{|c|}{ Sensitivity analysis } \\
\hline & $\begin{array}{l}\text { - Conclusions robust to changes in modelling covariates } \\
\text { - } \quad \text { Significant smoke-free effects only with long post-legislative } \\
\text { period } \\
\text { - Significant smoke-free effects for false legislation dates } \\
\text { between } 2005 \text { and } 2008\end{array}$ & $\begin{array}{l}\text { - } \quad \text { Conclusions robust to changes in modelling covariates } \\
\text { - No differences in conclusions as pre and post-legislative } \\
\text { periods vary } \\
\text { - No changes in conclusions for false legislation dates }\end{array}$ \\
\hline \multicolumn{3}{|c|}{ Interpretation } \\
\hline & $\begin{array}{l}\text { - Rate at which mortality declines decreases suddenly at } \\
\text { date of legislation } \\
\text { - } \quad \text { Model predicts additional deaths from late } 2008 \text { onwards }\end{array}$ & - $\quad$ Rate at which mortality declines is slowing gradually \\
\hline \multicolumn{3}{|l|}{ Evidence } \\
\hline & $\begin{array}{l}\text { Other studies have found significant smoke-free effects, } \\
\text { although not with an interaction } \\
\text { - } \quad \text { No other studies have predicted additional deaths } \\
\text { Estimated smoke-free effect is at the high end compared to } \\
\text { other studies }\end{array}$ & $\begin{array}{l}\text { - Evidence that the decline in mortality rates is flattening off } \\
\text { - Estimated (nonsignificant) smoke-free effect is a little low } \\
\text { compared to other studies }\end{array}$ \\
\hline
\end{tabular}




\section{REFERENCES}

[1] Barnoya J, Glantz SA. Cardiovascular Effects of Secondhand Smoke: Nearly as Large as Smoking. Circulation 2005; 111(20): 2684-98.

http://dx.doi.org/10.1161/CIRCULATIONAHA.104.492215

[2] Glantz S, Parmley W. Passive smoking and heart disease: Epidemiology, physiology, and biochemistry. Circulation 1991; 83(1): 1-12. http://dx.doi.org/10.1161/01.CIR.83.1.1

[3] Glantz SA, Parmley WW. Passive Smoking and Heart Disease: Mechanisms and Risk. JAMA 1995; 273(13): 104753.

http://dx.doi.org/10.1001/jama.1995.03520370089043

[4] He J, Vupputuri S, Allen K, Prerost MR, Hughes J, Whelton PK. Passive Smoking and the Risk of Coronary Heart Disease -- A Meta-Analysis of Epidemiologic Studies. N Engl J Med 1999; 340(12): 920-6. http://dx.doi.org/10.1056/NEJM199903253401204

MR, Morris JK, Wald NJ. Environmental tobacco smoke exposure and ischaemic heart disease: an evaluation of the evidence. Br Med J 1997; 315(7114): 973-80.

http://dx.doi.org/10.1136/bmj.315.7114.973

[6] Thun M, Henley J, Apicella L. Epidemiologic Studies of Fatal and Nonfatal Cardiovascular Disease and ETS Exposure from Spousal Smoking. Environ Health Perspect 1999; 107: 841-6.

[7] Wells A. Passive smoking as a cause of heart disease. J Am Coll Cardiol 1994; 24(2): 546-54. http://dx.doi.org/10.1016/0735-1097(94)90315-8

[8] Whincup PH, Gilg JA, Emberson JR, Jarvis MJ, Feyerabend $\mathrm{C}$, Bryant $\mathrm{A}$, et al. Passive smoking and risk of coronary heart disease and stroke: prospective study with cotinine measurement. Br Med J 2004; 329(7459): 200-5. http://dx.doi.org/10.1136/bmj.38146.427188.55

[9] Tan CE, Glantz SA. Association Between Smoke-Free Legislation and Hospitalizations for Cardiac, Cerebrovascular, and Respiratory Diseases: A MetaAnalysis. Circulation 2012; 126(18): 2177-83.

http://dx.doi.org/10.1161/CIRCULATIONAHA.112.121301

[10] Mackay DF, Irfan MO, Haw S, Pell JP. Meta-analysis of the effect of comprehensive smoke-free legislation on acute coronary events. Heart 2010; 96(19): 1525-30. http://dx.doi.org/10.1136/hrt.2010.199026

[11] Sims M, Maxwell R, Bauld L, Gilmore A. Short term impact of smoke-free legislation in England: retrospective analysis of hospital admissions for myocardial infarction. Br Med J 2010; 340: c2161.

[12] Sargent RP, Shepard RM, Glantz SA. Reduced incidence of admissions for myocardial infarction associated with public smoking ban: before and after study. $\mathrm{Br}$ Med $\mathrm{J} 2004$; 328(7446): 977-80. http://dx.doi.org/10.1136/bmj.38055.715683.55

[13] Shetty KD, DeLeire T, White C, Bhattacharya J. Changes in US hospitalization and mortality rates following smoking bans. J Policy Anal Manage 2011; 30(1): 6-28.

http://dx.doi.org/10.1002/pam.20548

[14] Agüero F, Dégano IR, Subirana I, Grau M, Zamora A, Sala J, et al. Impact of a Partial Smoke-Free Legislation on Myocardial Infarction Incidence, Mortality and Case-Fatality in a Population-Based Registry: The REGICOR Study. PloS One 2013; 8(1): e53722.

http://dx.doi.org/10.1371/journal.pone.0053722

[15] Ford ES, Capewell S. Coronary Heart Disease Mortality Among Young Adults in the U.S. From 1980 though 2002: concealed leveling of mortality rates. J Am Coll Cardiol 2007; 50(22): 2128-32.

http://dx.doi.org/10.1016/j.jacc.2007.05.056
[16] Maclntyre K, Murphy NF, Chalmers J, Capewell S, Frame S, Finlayson $A$, et al. Hospital burden of suspected acute coronary syndromes: recent trends. Heart 2006; 92(5): 6912. http://dx.doi.org/10.1136/hrt.2005.068742

[17] Marques-Vidal P, Ruidavets J-B, Cambou J-P, Ferrieres J. Incidence, recurrence, and case fatality rates for myocardial infarction in southwestern France, 1985 to 1993. Heart 2000; 84(2): 171-5. http://dx.doi.org/10.1136/heart.84.2.171

[18] Tu JV, Nardi L, Fang J, Liu J, Khalid L, Johansen H, et al. National trends in rates of death and hospital admissions related to acute myocardial infarction, heart failure and stroke, 1994-2004. CMAJ 2009; 180(13): E118-25. http://dx.doi.org/10.1503/cmaj.081197

[19] Lemstra M, Neudorf C, Johnmark O. Implications of a Public Smoking Ban. Can J Public Health 2008; 99(1): 62-5.

[20] Johnson EL, Beal JR. Impact of a comprehensive smokefree law following a partial smoke-free law on incidence of heart attacks at a rural community hospital. Nicotine Tob Res 2013; 15(3): 745-7.

http://dx.doi.org/10.1093/ntr/nts216

[21] Barone-Adesi F, Gasparrini A, Vizzini L, Merletti F, Richiardi L. Effects of Italian smoking regulation on rates of hospital admission for acute coronary events: a country-wide study. PLoS One 2011; 6: e17419. http://dx.doi.org/10.1371/journal.pone.0017419

[22] Cesaroni G, Forastiere F, Agabiti N, Valente P, Zuccaro P, Perucci CA. Effect of the Italian Smoking Ban on Population Rates of Acute Coronary Events. Circulation 2008; 117(9): 1183-8. http://dx.doi.org/10.1161/CIRCULATIONAHA.107.729889

[23] Herman PM, Walsh ME. Hospital Admissions for Acute Myocardial Infarction, Angina, Stroke, and Asthma After Implementation of Arizona's Comprehensive Statewide Smoking Ban. Am J Public Health 2011; 101(3): 491-6. http://dx.doi.org/10.2105/AJPH.2009.179572

[24] Juster HR, Loomis BR, Hinman TM, Farrelly MC, Hyland A Bauer UE, et al. Declines in Hospital Admissions for Acute Myocardial Infarction in New York State After Implementation of a Comprehensive Smoking Ban. Am J Public Health 2007; 97(11): 2035-9. http://dx.doi.org/10.2105/AJPH.2006.099994

[25] Naiman A, Glazier RH, Moineddin R. Association of antismoking legislation with rates of hospital admission for cardiovascular and respiratory conditions. CMAJ 2010; 182(8): 761-7. http://dx.doi.org/10.1503/cmaj.091130

[26] Villalbí JR, Sánchez E, Benet J, Cabezas C, Castillo A Guarga A, et al. The extension of smoke-free areas and acute myocardial infarction mortality: before and after study. BMJ Open 2011; 1: e000067. http://dx.doi.org/10.1136/bmjopen-2011-000067

[27] Dove MS, Dockery DW, Mittleman MA, Schwartz J, Sullivan EM, Keithly L, et al. The impact of Massachusetts' smokefree workplace laws on acute myocardial infarction deaths. Am J Public Health 2010; 100(11): 2206. http://dx.doi.org/10.2105/AJPH.2009.189662

[28] Stallings-Smith S, Zeka, A., Goodman, P., Kabir, Z., Clancy, L. Reductions in Cardiovascular, Cerebrovascular, and Respiratory Mortality Following the National Irish Smoking Ban: Interrupted Time-Series Analysis. PLoS One 2013; 8: e62063. http://dx.doi.org/10.1371/journal.pone.0062063

[29] Rodu B, Peiper N, Cole P. Acute Myocardial Infarction Mortality Before and After State-wide Smoking Bans. J Community Health 2012; 37(2): 468-72. http://dx.doi.org/10.1007/s10900-011-9464-5 
[30] Barr CD, Diez DM, Wang Y, Dominici F, Samet JM. Comprehensive Smoking Bans and Acute Myocardial Infarction Among Medicare Enrollees in 387 US Counties: 1999-2008. Am J Epidemiol 2012; 176(7): 642-8. http://dx.doi.org/10.1093/aje/kws267

[31] Gasparrini A, Gorini G, Barchielli A. On the relationship between smoking bans and incidence of acute myocardial infarction Eur J Epidemiol 2009; 24: 597-602. http://dx.doi.org/10.1007/s10654-009-9377-0

[32] US Institute of Medicine. Secondhand Smoke Exposure and Cardiovascular Effects: Making Sense of the Evidence. Washington DC: US Institute of Medicine, 2010.

[33] Crawford VLS, Mccann M, Stout RW. Changes in seasonal deaths from myocardial infarction. QJM 2003; 96(1): 45-52. http://dx.doi.org/10.1093/ajmed/hcg005
[34] Douglas AS, Dunnigan MG, Allan TM, Rawles JM. Seasonal variation in coronary heart disease in Scotland. $\mathrm{J}$ Epidemiol Community Health 1995; 49(6): 575-82. http://dx.doi.org/10.1136/jech.49.6.575

[35] Kloner RA. The "Merry Christmas Coronary" and "Happy New Year Heart Attack" Phenomenon. Circulation 2004; 110(25): 3744-5.

http://dx.doi.org/10.1161/01.CIR.0000151786.03797.18

[36] Pell JP, Cobbe SM. Seasonal variations in coronary heart disease. QJM 1999; 92(12): 689-96. http://dx.doi.org/10.1093/qjmed/92.12.689

[37] Luepker R, Berger A. Is acute myocardial infarction disappearing? Circulation 2010; 121(11): 1280-2. http://dx.doi.org/10.1161/CIR.0b013e3181d98478

Received on 01-01-2014

Accepted on 31-01-2014

Published on 10-02-2014

http://dx.doi.org/10.6000/1929-6029.2014.03.01.7

(C) 2014 Salway et al.; Licensee Lifescience Global.

This is an open access article licensed under the terms of the Creative Commons Attribution Non-Commercial License (http://creativecommons.org/licenses/by-nc/3.0/) which permits unrestricted, non-commercial use, distribution and reproduction in any medium, provided the work is properly cited. 